\title{
CENTRO DE SERVIÇOS COMPARTILHADOS EM MODELO PRÓPRIO OU TERCEIRIZADO: UM ESTUDO COMPARATIVO MULTICASOS
}

\author{
SHARED SERVICE CENTER IN THE IN-HOUSE OR OUTSOURCED MODEL: A COMPARATIVE, \\ MULTICASE STUDY \\ CENTRO DE SERVICIOS COMPARTIDOS EN MODELO PROPIO O TERCERIZADO: UN ESTUDIO \\ COMPARATIVO MULTICASOS
}

\author{
HENRIQUE JOSÉ AFFONSO \\ Doutorando \\ Universidade Fundação Mineira de Educação e Cultura - Brasil \\ hjaffonso@ig.com.br \\ HENRIQUE CORDEIRO MARTINS \\ Doutor \\ Universidade Fundação Mineira de Educação e Cultura - Brasil \\ henrique.martins@fumec.br
}

CARLOS ALBERTO GONÇALVES

Doutor

Universidade Federal de Minas Gerais - Brasil carlos@face.ufmg.br

Submetido em: 12/07/2012

Aprovado em: 27/06/2014

Doi: alcance.v22n2.p197-211

\section{RESUMO}

O objetivo desse artigo foi analisar os impactos da implementação de Centro de Serviços Compartilhados (CSC) na estratégia, na estrutura e na gestão de empresas do setor privado, considerando sua configuração de operação como unidade da própria empresa ou como unidade terceirizada. A pesquisa foi de natureza qualitativa, realizada por meio de estudos de casos em duas grandes empresas sediadas em Minas Gerais, utilizando-se principalmente de entrevistas semiestruturadas, realizadas com 13 gestores. Os resultados apontam que o CSC permite que a empresa foque em suas competências centrais com aumento da vantagem competitiva na sua cadeia de valor, porém a otimização dos resultados e a facilidade no aprimoramento da gestão foram mais notadas em CSC operado pela própria organização, em detrimento ao CSC terceirizado.

Palavras-chave: Centro de Serviços Compartilhados (CSC). Eficiência organizacional. Terceirização (outsourcing) de atividades de apoio (back office).

\section{ABSTRACT}

The objective of this study was to analyze the impacts of the implementation of the Shared Services Center (CSC) on strategy, structure and business management in the private sector, considering its operating configuration as a unit of the company itself or as an outsourced unit. The research was qualitative, through case studies in two major companies based in Minas Gerais, using mainly semi-structured interviews conducted with thirteen managers. The results show that the CSC allows the company to focus on its core competencies, with increased competitive advantage in its value chain; however, optimization of the results and the ease of management improvement were most noticeable in the CSC operated by the organization itself, to the detriment of the outsourced CSC. 
Keywords: Shared Services Center (CSC). Organizational efficiency. Outsourcing of support activities (back office).

\section{RESUMEN}

El objetivo de este artículo fue analizar los impactos de la implementación del Centro de Servicios Compartidos (CSC) en la estrategia, en la estructura y en la gestión de empresas del sector privado, considerando su configuración de operación como unidad de la propia empresa o como unidad tercerizada. La investigación fue de naturaleza cualitativa, realizada por medio de estudios de casos en dos grandes empresas situadas en Minas Gerais, utilizando principalmente entrevistas semiestructuradas realizadas con 13 gestores. Los resultados señalan que el CSC permite que la empresa se concentre en sus competencias centrales con un aumento de la ventaja competitiva en su cadena de valor, aunque la optimización de los resultados y la facilidad en el perfeccionamiento de la gestión fueron más notadas en el CSC operado por la propia organización, en detrimento del CSC tercerizado.

Palabras clave: Centro de Servicios Compartidos (CSC). Eficiencia organizacional. Tercerización (outsourcing) de actividades de apoyo (back office).

\section{INTRODUÇÃO}

As pressões de um mundo globalizado por inovações tecnológicas, reduções de custos, produtos mais baratos e com muito mais qualidade, entre outras variáveis, exigem que as corporações tomem decisões estratégicas, flexibilizando, muitas vezes, suas ações, para que possam agregar valores aos seus negócios, visando torná-los competitivos. As empresas estão sofrendo também transformações em suas estruturas organizacionais e a utilização de Centro de Serviços Compartilhados (Shared Services) - CSC constitui-se em uma dessas transformações

Este novo cenário torna o planejamento estratégico uma disciplina fundamental a ser resgatada no ambiente empresarial. Entre as diversas linhas de ação propostas no campo do planejamento estratégico, a otimização dos recursos é, muitas vezes, um dos poucos caminhos para ganhar competitividade para as empresas quando a lucratividade e as vendas estão declinando. Nessa situação, uma das questões essenciais à empresa refere-se ao estabelecimento de formas de organizar os negócios que permitam o sucesso das metas estratégicas e a liberação de recursos para as atividades essenciais (SILVA; PEREIRA, 2004).

Segundo Schulman, Harmer e Lusk (2001), a crescente onda de fusões e aquisições chamou atenção para a possibilidade de enxugar as operações corporativas e transacionais que não fazem parte do chamado "core business" das organizações. Ao mesmo tempo, o avanço tecnológico possibilitou estruturas e tipos de fornecimento de serviços cada vez mais inovadores, com destaque para o outsourcing. No entanto, as organizações perceberam a possibilidade de criar mercados internos e unidades semiautônomas, cuja competitividade e foco no cliente aumentariam significativamente a qualidade do serviço. Foi nesse sentido que o debate sobre 0 Centro de Serviços Compartilhados tem aumentado, prática que já vem sendo observada há mais de 20 anos.

Esses "Centros" são entendidos como um modelo de organização de processos operacionais pelos quais uma área específica da empresa presta serviços a partir de um mesmo ponto de atendimento para as demais unidades da organização.

As atividades realizadas no CSC são justamente aquelas que não fazem parte de competências centrais, já que essas são atividades de apoio, cujo valor não é percebido pelo cliente como diferenciador (SCHULMAN; HARMER; LUSK, 2001).

Para Ramos (2005), os Serviços Compartilhados buscam obter os benefícios da terceirização, tais como flexibilidade, foco e economia de escala, suprimindo seus principais riscos como perda do conhecimento e do poder de execução, descontrole dos custos e do risco de descumprimento de normas e legislações. Entretanto, problemas podem surgir envolvendo empregados; procedimentos; tecnologia necessária ao novo ambiente; alteração do ambiente de trabalho, os quais impactam e ao mesmo tempo são influenciados pela 
cultura da corporação e suas dinâmicas organizacionais; bem como os decorrentes da instituição de controles e de indicadores da empresa (SCHULMAN; HARMER; LUSK, 2001).

Essas dificuldades, bem como as vantagens esperadas pela existência do modelo, são concretizadas pela forma de como o Centro de Serviço Compartilhado (CSC) é concebido e implementado. Nesse sentido, as características de o CSC operar como unidade da própria organização, ou ser operado por empresa terceirizada, podem acarretar diferentes consequências para que tal modelo se torne uma solução e acarrete ganhos para a organização, e não mais um modismo cuja experiência pode ser bastante custosa.

A importância e a pluralidade de características que envolvem o modelo de CSC no contexto organizacional ensejam a expectativa de enriquecer a literatura, considerada ainda escassa sobre o tema, com análises sobre a efetividade e o estudo dos impactos do modelo de CSC nas empresas. Dessa forma, objetiva este artigo analisar os impactos da implementação de CSC na estratégia, na estrutura e na gestão de empresas do setor privado, considerando sua configuração de operação como unidade da própria empresa ou como unidade terceirizada (outsourcing).

\section{FUNDAMENTAÇÃO TEÓRICA}

\subsection{Centro de Serviços Compartilhados (CSC)}

$\mathrm{Na}$ tentativa de capturar a intenção e o ideal do modelo administrativo-financeiro compartilhado, Bergeron (2003) define-o como uma estratégia, na qual diversas funções de negócios existentes são concentradas dentro de uma nova e semiautônoma unidade de negócio, que tem uma estrutura gerencial designada para promover eficiência, geração de valor, redução de custo e melhoria nos serviços para clientes internos da organização.

Nesse contexto, os chamados Shared Services Center (Centros de Serviços Compartilhados - CSCs) acabaram por se estabelecerem como uma solução comprovada de aumento da eficiência operacional com redução dos custos (LOZINSKY, 2006), bem como uma relação fornecedor/cliente com as unidades de negócio, utilizando-se de índices de desempenho quantificados para influenciar o comportamento e mensurar os resultados (VECTOR CONSULTING, 2009).

As principais razões pelas quais as empresas adotam um CSC não são somente os mensuráveis/tangíveis, mas também os de ganho de qualidade, nem sempre passíveis de controle e mensuração, como os casos dos intangíveis. Como mensuráveis, podem ser citados: redução de despesas, aumento da produtividade, economias de escala, alavancagem de tecnologia, maior controle, aumento do capital de giro, alavancagem das compras pela consolidação de fornecedores; como intangíveis: melhoria dos serviços aos parceiros/clientes; padronização de processos e grupo de recursos; abordagem "uma empresa"; transição mais rápida, focando-se em "valor agregado"; manutenção mais eficaz dos padrões do "bloco de códigos"; melhoria da acuracidade e da uniformidade das informações; melhor alavancagem da curva de aprendizado (SCHULMAN, HARMER E LUSK, 2001).

Em contraponto das razões/vantagens para adoção de um CSC, a complexidade desse tipo de aliança oferece um desafio à administração, demandando novas qualificações entre os administradores e profissionais (SILVA E PEREIRA, 2004), ainda evocando toda uma variedade de situações e problemas organizacionais, tais como: gestão de parcerias, acordo de serviços prestados, a complexidade do ambiente, a segurança dos serviços, o clima organizacional, a relação cliente fornecedor, transferência de conhecimento, tecnologia e a mudança cultural.

Além disso, iniciativas do gênero requerem um esforço contínuo de aprimoramento (MARTINS; AMARAL, 2008), tais como: incluir a formação de uma cultura efetivamente orientada para 0 usuário dos serviços; automatizar as práticas manuais; mensurar permanentemente os benefícios; monitorar as tarefas e, principalmente, transformar o modo de atuar das pessoas na organização.

Considerando a teorização de Quinn, Cooke, Kris, 2000 apud Ramos (2005), existiriam quatro modelos de Centro de Serviços Compartilhados: Básico, MarketPlace, MarketPlace Avançado e Empresa Independente (o Quadro 1 mostra a evolução dos modelos de Serviços Compartilhados, sendo que tal evolução decorre do tempo de existência, de amadurecimento e da forma de gerenciamento/objetivos do CSC na organização, geralmente ocorrendo de forma gradativa e baseados no ciclo de aprendizagem e aprimoramento do modelo).

Revista Alcance - Eletrônica - vol. 22 - n. 2 - abr.jun. 2015 
QUADRO 1: Evolução dos modelos de Centros de Serviços Compartilhados

\begin{tabular}{|c|c|c|c|c|}
\hline MODELO & BÁSICO & MARKETPLACE & $\begin{array}{l}\text { MARKETPLACE } \\
\text { AVANÇADO }\end{array}$ & $\begin{array}{l}\text { EMPRESA } \\
\text { INDEPENDENTE }\end{array}$ \\
\hline \multirow{3}{*}{ Características } & $\begin{array}{l}\text { Consolidação das } \\
\text { transações } \\
\text { atividades de apoio. }\end{array}$ & $\begin{array}{l}\text { Inclui o fornecimento } \\
\text { de serviços } \\
\text { especializados } \\
\text { /consultoria. }\end{array}$ & $\begin{array}{l}\text { O cliente escolhe seu } \\
\text { fornecedor. }\end{array}$ & $\begin{array}{l}\text { Várias empresas } \\
\text { clientes. }\end{array}$ \\
\hline & $\begin{array}{l}\text { Economia de } \\
\text { Escala. }\end{array}$ & $\begin{array}{l}\text { Organização } \\
\text { estrutura a própria } \\
\text { governança. }\end{array}$ & $\begin{array}{l}\text { Fornecimento de } \\
\text { serviços com } 0 \\
\text { repasse dos custos. }\end{array}$ & $\begin{array}{l}\text { Objetivo é o lucro } \\
\text { com a prestação de } \\
\text { serviços. }\end{array}$ \\
\hline & $\begin{array}{lr}\text { Os custos } & \text { de } \\
\text { serviços } & \text { são } \\
\text { apropriados, } & \text { mas } \\
\text { não são repassados } \\
\text { aos r clientes } \\
\text { internos. }\end{array}$ & $\begin{array}{l}\text { Custos totalmente } \\
\text { repassados para as } \\
\text { unidades de negócio. }\end{array}$ & $\begin{array}{l}\text { Possibilidade de } \\
\text { venda de serviços a } \\
\text { clientes externos se } \\
\text { a capacidade } \\
\text { produtiva for } \\
\text { excedente. }\end{array}$ & $\begin{array}{l}\text { Atuação como } \\
\text { empresa } \\
\text { independente. }\end{array}$ \\
\hline Objetivo & $\begin{array}{lr}\text { Reduzir custos } & \text { e } \\
\text { padronizar } & \\
\text { processos } & \text { de } \\
\text { produção } & \text { dos } \\
\text { serviços. } & \end{array}$ & $\begin{array}{l}\text { Reduzir custos e } \\
\text { melhorar qualidade } \\
\text { dos serviços. }\end{array}$ & $\begin{array}{l}\text { Oferecer a melhor } \\
\text { alternativa em custos } \\
\text { e serviços. }\end{array}$ & $\begin{array}{lr}\text { Gerar receitas e } \\
\text { lucros como uma } \\
\text { empresa } & \text { de } \\
\text { serviços. } & \end{array}$ \\
\hline $\begin{array}{l}\text { Forma de } \\
\text { relacionamento }\end{array}$ & $\begin{array}{l}\text { Utilização } \\
\text { Compulsória dos } \\
\text { serviços pelas } \\
\text { unidades de } \\
\text { negócio }\end{array}$ & Utilização voluntária. & Utilização voluntária. & $\begin{array}{l}\text { Utilização } \\
\text { voluntária. }\end{array}$ \\
\hline
\end{tabular}

Fonte: Adaptado de Quinn, Cooke e Kris (2000) apud Ramos (2005).

O CSC pode constituir-se na formatação de uma unidade da própria organização, também chamado de "terceirização interna" (insourcing), ou na formatação de prestação de serviços por empresa externa à organização, também chamado de "terceirização externa" (outsourcing).

A definição da formatação do CSC em relação à prestação dos serviços compartilhados implica características peculiares e inerentes a cada forma de terceirização dos serviços e acarreta diferenciadas consequências para a manutenção, a gestão, os resultados e a efetiva capacidade de atendimento às necessidades das áreas clientes e da organização a longo prazo.

Nesse sentido, a "terceirização externa" do CSC é um assunto tratado na teoria com certa reserva e orientações de análises cuidadosas para tal decisão, conforme inclusive apresentado por Schulman, Harmer e Lusk (2001), os quais observam que, devido ao fato de as empresas que prestam serviços terceirizados sempre procurarem recuper seus custos, pode ser relativamente barato entrar na terceirização, mas quase sempre caro mantê-la pelo tempo todo.

\subsection{Impactos do CSC nas estratégicas e nas estruturas organizacionais}

Quando executados corretamente, os serviços compartilhados realmente impulsionam as operações das Unidades de negócio focadas nas partes estratégicas de sua operação, enquanto os demais processos não estratégicos são prestados com a eficiência esperada pelo CSC (SCHULMAN; HARMER; LUSK, 2001).

Demonstrando que a habilidade de compartilhar atividades é uma base potente para a estratégia empresarial, Porter (1998) considera que o compartilhamento realça frequentemente a vantagem competitiva ao diminuir os custos ou ao aumentar a diferenciação; enquanto Pereira (2004) destaca que a busca de alternativas para redução de custos, de forma mais dinâmica de trabalho, de maior capacidade competitiva, priorizando a 
alocação dos recursos nas atividades com maior potencial de lucro, exige que as estratégias empresariais sejam elaboradas com profunda reflexão e análise de toda a cadeia de valor.

A diferença entre Serviços Compartilhados e terceirização, na visão de Silva, Santos e Santos (2006), é que esta consiste em entregar parte das atividades ou até mesmo uma área inteira para outra empresa especializada realizar os serviços; e aqueles consistem em uma "terceirização interna", em que atividades realizadas de forma descentralizada pela organização são concentradas em um mesmo ambiente para serem compartilhadas com as demais unidades de negócio da empresa, sendo os recursos utilizados, neste caso, os da própria empresa.

Em relação à estrutura de um CSC, Magalhães (2009) ressalta a necessidade de serem analisadas diversas questões relacionadas à definição do local de funcionamento, bem como das características das instalações do Centro, além do que, considerando o posicionamento de um CSC em relação ao modelo de governança, no tocante à subordinação hierárquica do Centro, o modelo de governança deve ser definido para garantir a eficiência dos serviços prestados à empresa e à "regra do jogo" dos serviços, observando os prós e contras dos diversos modelos de governança (modelo baseado na visão financeira; modelo baseado em Departamento; modelo baseado em Unidade de Negócio Independente; modelo baseado em Holding corporativo), conforme Figura 1.

Figura 1: Modelos de governança para um CSC

\begin{tabular}{|c|c|c|c|}
\hline \multicolumn{2}{|c|}{ Modelo Hierárquico } & Prós & Contra \\
\hline $\begin{array}{l}\text { Modelo baseado na } \\
\text { Visão Financeira }\end{array}$ & $\frac{1}{15}$ & $\begin{array}{l}\text { - Alto controle fnancelro } \\
\text { : Boa gest5o de numeros } \\
\text { : Foco em controle } \\
\text { - Foco em reduçato de custos }\end{array}$ & 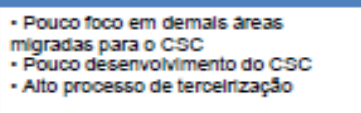 \\
\hline $\begin{array}{l}\text { Modelo Baseado em } \\
\text { Departamento }\end{array}$ & & $\begin{array}{l}\text { - Utizza connecimento da unidade } \\
\text { escolnida } \\
\text { P Parronizaç̧o baseada no modelo da } \\
\text { UM. }\end{array}$ & 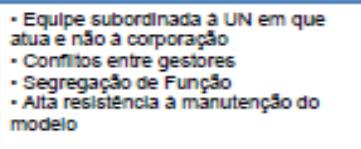 \\
\hline $\begin{array}{l}\text { Modelo baseado em Unidade } \\
\text { de Negócio Independente }\end{array}$ & & $\begin{array}{l}\text { - Independencla de gestato } \\
\text { - Foco em desenvolvimento do negocio } \\
\text { - Foco em Supotio ao Clente } \\
\text { - Focoem melhoria Contlinua para } \\
\text { sobreviver as mudanças do negoclo. }\end{array}$ & 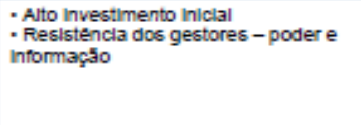 \\
\hline $\begin{array}{l}\text { Modelo baseado em Holing } \\
\text { (Corporativo) }\end{array}$ & $\csc$ & $\begin{array}{l}\text {-Foco no controle do negoclo } \\
\text {-Ealxa resistencla dos gestores } \\
\text { Foco em serviços de gestá de } \\
\text { desempento e relatorios corporativos }\end{array}$ & $\begin{array}{l}\text {-Pouco foco em desenvolver areas que } \\
\text { geram valor ao negoclo. } \\
\text { - CsC tende a deservolver-se como } \\
\text { Controladoria. }\end{array}$ \\
\hline
\end{tabular}

Fonte: Magalhães (2009, p. 30).

\subsection{Impactos do CSC na gestão organizacional}

\subsubsection{Gestão de Processos}

Na visão da questão dos processos em CSC, ressalta Shah (1998) que o passo para serviços compartilhados envolve uma revisão dos atuais processos e um desenho de novas atividades baseadas nas melhores práticas, internas ou externas, e em entrega de valor.

Bergeron (2003) destaca que a operação de serviços compartilhados requer alguns outros atributos como: operar como uma organização autônoma; estar orientada a processos e focalizar atividades específicas dentro do processo; alavancar os investimentos tecnológicos; focalizar o serviço e o suporte aos parceiros do negócio, indo além das noções tradicionais de "serviço ou suporte ao cliente"; e focalizar a melhoria contínua. Salienta também alguns obstáculos que podem surgir na implantação da nova estrutura: limitações dos sistemas existentes para atender às novas demandas das unidades de negócios e os respectivos fluxos de informações; a falta de compromisso do corpo executivo e a supracitada resistência à mudança da estrutura descentralizada para a compartilhada.

A visão orientada por processos se mostra quase mandatória no CSC, que passa a ter objetivos e

Revista Alcance - Eletrônica - vol. 22 - n. 2 - abr.jun. 2015 
clientes muito bem definidos para a execução de suas tarefas. Para isso, é preciso transformar os processos que acontecem em diversos lugares para um modelo padrão de unidade de serviços. Além da padronização de processos, a unificação desses serviços de apoio também implica a uniformização de ferramentas e aplicativos. A maior vantagem da padronização de processos e sistemas está intrinsecamente ligada à melhoria do nível de serviço (SHAH, 1998).

Abordando sobre o esforço de redesenho dos processos e da organização, Bain \& Company (2004) expõem que talvez um dos maiores benefícios de um CSC é a oportunidade de "remontar" a organização em torno dos processos e não das funções.

\subsubsection{Gestão de Pessoas}

Os componentes pessoas e cultura demandam um processo de gerenciamento do projeto e da mudança que envolve vários aspectos do relacionamento pessoal, tais como: resistência a mudanças, confiança, motivação, redução de pessoal, engajamento, relação sindical, multicidade de culturas, entre outros (RAMOS, 2005).

Sabe-se que grande parte do aumento de produtividade que se obtém do CSC é devido à massiva redução de pessoal que se consegue ao juntar estas mesmas atividades de apoio. Aliado a isso, é necessário, também, definir as melhores pessoas para realizar essas atividades, garantindo o máximo de qualidade no serviço prestado. Essa realocação pode criar um clima de oposição, pois pode haver um sentimento de que os funcionários remanejados para fora das UN's não sejam tão importantes (BERGERON, 2003).

Nesse sentido, a visão de satisfação do cliente e busca pela excelência operacional demandam com que os empregados do CSC sintam-se como membros de uma empresa prestadora de serviços, da mesma forma que os de fora - demais empregados das demais unidades de negócios - a veem como uma entidade independente (SILVA; SANTOS; SANTOS, 2006).

Ainda para exemplificar as atenções a serem dadas à gestão de pessoas, Schulman, Harmer e Lusk (2001) explanam que os problemas podem surgir com a resistência das pessoas; a alteração das políticas e dos procedimentos; mudanças da tecnologia necessária ao novo ambiente, mexendo ainda com a cultura da corporação e suas dinâmicas organizacionais, bem como os controles e os indicadores da empresa.

\subsubsection{Gestão da mudança}

No que tange à adoção do modelo de CSC, autores como Schulman, Harmer e Lusk (2001) consideram que a parte mais importante de qualquer implementação de uma grande mudança no negócio é a comunicação, e o comprometimento da alta administração é imprescindível para o sucesso do projeto. Sem este patrocínio, os resultados não são obtidos e a iniciativa tende a cair no vazio com altos riscos financeiros e políticos.

No mesmo sentido, Martins e Amaral (2008) consideram que a implantação de um CSC requer o planejamento adequado, determinando as etapas e os objetivos a serem alcançados, além de forte estratégia de comunicação patrocinada pela alta direção da empresa. Para esses autores, as organizações têm subestimado, durante a implementação dos CSC, os esforços que seriam necessários às ações cruciais do projeto, como 0 treinamento de pessoas aos novos procedimentos, as implicações culturais contidas na mudança, a comunicação entre os profissionais e o alinhamento estratégico dos profissionais.

Como alerta para a importância da adequada gestão da mudança nos projetos de adoção e implementação desse modelo, tem-se, a partir de levantamento realizado sobre os motivos pelos quais esses tipos de projetos falham, que dentre as dez principais barreiras para o sucesso para o CSC, seis são diretamente relacionadas com o gerenciamento da mudança (MAGALHÃES, 2009).

\section{METODOLOGIA DE PESQUISA E DESCRIÇÃO DOS CASOS}

Para o estudo apresentado neste artigo, a metodologia de pesquisa utilizada foi de natureza qualitativa, com estudo de casos múltiplos, utilizando-se de entrevista semiestruturada como instrumento principal de coleta de dados e técnica de análise de conteúdo para análise das entrevistas. As empresas participantes foram a ALGAR S.A. (Uberlândia - MG) e a ALCOA (Poços de Caldas - MG). 
Trata-se de uma investigação que se utilizou de entrevista semiestruturada como instrumento principal de coleta de dados, que possibilitou a participação, a compreensão e a interpretação dos pesquisadores. Para análise dos dados colhidos nas entrevistas, utilizou-se como referência a análise de conteúdo, conforme definição de Bardin (2004). A partir da literatura levantada sobre o tema, as categorias de análise dos dados versaram sobre as seguintes dimensões: estratégias para adoção do modelo; contexto de implementação; estrutura organizacional; gestão de processos e gestão de pessoas.

Na empresa ALGAR S.A., que possui um Centro de Serviços Compartilhados totalmente terceirizado, gerido pela empresa TOUTATIS S.A., não se mostraram necessárias, por exemplo, entrevistas com os empregados do CSC, visto que não eram empregados da ALGAR S.A., sendo realizadas ao todo seis entrevistas: uma com executivo/implementador; três com áreas clientes; duas com gestores do CSC. No caso da ALCOA S.A., que possui CSC denominado internamente GBS (Global Business Services) como unidade autônoma pertencente ao próprio grupo, foram realizadas sete entrevistas: uma com executivo/implementador; duas com áreas clientes; duas com gestores e duas com empregados do CSC.

A ALGAR S.A. é um grupo empresarial empreendedor que atua nos setores de TI/Telecom, Agro, Serviços e Turismo, composto por nove empresas, contando mais de 16 mil empregados, estando presente na vida de mais de 1.000 cidades nos estados de Minas Gerais, Goiânia, Distrito Federal, São Paulo, Rio de Janeiro, Rio Grande do Sul e Maranhão. O grupo ALGAR trabalha com o conceito de "Governança Invisível", que diz respeito aos processos que ajudam a manter uma relação saudável entre acionistas e executivos da empresa. No Grupo ALGAR, existem três holdings familiares (Elgar, Lagar e Walgar), que acompanham os processos decisórios da empresa por meio do Conselho de Família e de um Conselho Fiscal. O Centro de Serviços Compartilhados da ALGAR centraliza em uma única empresa terceirizada os serviços de back office de todas as empresas da holding, estando localizado na cidade de Uberlândia.

A ALCOA S.A. é a líder mundial entre os produtores de alumínio primário, alumínio industrializado e alumina, sendo responsável por meio de suas inovações, além de ter criado a atual indústria de alumínio, pelas maiores realizações dos mercados automotivo, aeroespacial, de embalagens, de construção, de transporte comercial, de produtos eletrônicos e industriais dos últimos 120 anos. A ALCOA faz parte do índice de sustentabilidade Dow Jones pelo oitavo ano consecutivo e aproximadamente $75 \%$ de todo alumínio já produzido desde 1888 ainda está em uso hoje. A ALCOA emprega aproximadamente 59.000 pessoas em 31 países no mundo todo, apresentando uma receita em 2009 na ordem de US\$ 18,4 bilhões. Suas atividades apresentam a seguinte configuração por área geográfica: $52 \%$ - Estados Unidos; $27 \%$ - Europa; $15 \%$ - Pacífico e $6 \%$ - Outras Américas. O CSC da ALCOA chama-se Global Business Services (GBS) e visa propiciar mais agilidade e qualidade às atividades da Companhia.

\section{COMPARANDO OS CSCS DOS CASOS ESTUDADOS}

Após a apresentação dos referenciais teóricos sobre do CSC não somente em relação aos impactos nas dimensões consideradas, mas também quanto às abordagens sobre o seu funcionamento como unidade autônoma da própria empresa ou como unidade terceirizada, a pesquisa foi realizada conforme descrita no item de metodologia, viabilizando a obtenção dos resultados e das análises a seguir expostos.

\subsection{Benefícios e dificuldades da ALGAR e da ALCOA em relação ao CSC}

Os principais benefícios e dificuldades destacados pelos entrevistados na ALGAR e na ALCOA com relação ao CSC estão listados nos Quadros 2 e 3, respectivamente, a seguir apresentados. 
Quadro 2: Benefícios e dificuldades da ALGAR em relação ao CSC

\begin{tabular}{|l|lll|}
\hline \multicolumn{1}{|c|}{ BENEFÍCIOS } & \multicolumn{3}{|c|}{ DIFICULDADES } \\
\hline Custo menor do que manter uma estrutura interna & $\begin{array}{l}\text { Relacionamento ruim; deficiências de comunicação; } \\
\text { problemas na prestação do serviço. }\end{array}$ \\
\hline $\begin{array}{l}\text { Continuidade e impessoalidade na execução das } \\
\text { atividades de back office. }\end{array}$ & $\begin{array}{l}\text { Não consideração de aspectos da terceirização pelos } \\
\text { gestores. }\end{array}$ \\
\hline $\begin{array}{l}\text { Retirada das atividades operacionais da } \\
\text { organização, possibilitando foco nos negócios das } \\
\text { áreas. }\end{array}$ & Falta de melhor qualificação dos empregados do CSC. & \\
\hline $\begin{array}{l}\text { Diminuição de custos para a ALGAR no que } \\
\text { tange à execução das atividades. }\end{array}$ & $\begin{array}{l}\text { Dispersão; mudanças; deficiências no contrato e } \\
\text { governança. }\end{array}$ \\
\hline $\begin{array}{l}\text { Terceirização também dos riscos operacionais } \\
\text { (multas, penalidades) para o CSC. }\end{array}$ & & & \\
\hline
\end{tabular}

Fonte: Dados da pesquisa.

Quadro 3: Benefícios e dificuldades da ALCOA em relação ao CSC

\begin{tabular}{|l|l|}
\hline \multicolumn{1}{|c|}{ BENEFíCIOS } & \multicolumn{1}{|c|}{ DIFICULDADES } \\
\hline Facilidade na obtenção de informações junto ao CSC. & $\begin{array}{l}\text { Eventuais necessidades de uniformização de } \\
\text { processos pelo CSC. }\end{array}$ \\
\hline $\begin{array}{l}\text { Pessoas no CSC especializadas nos assuntos que } \\
\text { envolvem as atividades de back office, desonerando } \\
\text { área cliente. }\end{array}$ & Falta de maior contato físico. \\
\hline $\begin{array}{l}\text { Facilidade em tratar determinada necessidade da } \\
\text { organização, mesmo partindo de diversas áreas } \\
\text { clientes, um objetivo único, com uma parceria de } \\
\text { prioridade com o CSC. }\end{array}$ & $\begin{array}{l}\text { Garantir que as partes envolvidas cumpram os } \\
\text { procedimentos conforme previstos e acordados. }\end{array}$ \\
\hline $\begin{array}{l}\text { Centralização e padronização; valorização das } \\
\text { pessoas e integração. }\end{array}$ & \\
\hline $\begin{array}{l}\text { Existência de metas, controles e acompanhamentos } \\
\text { para que os direitos e os deveres sejam efetivamente } \\
\text { cumpridos. }\end{array}$ & \\
\hline
\end{tabular}

Fonte: Dados da pesquisa.

\subsection{Avaliações sobre os principais pontos dos CSCs das empresas}

Análises comparativas entre os principais pontos abordados quanto à avaliação do CSC em cada empresa pesquisada são apresentadas no Quadro 4. 
Quadro 4: Quadro comparativo quanto às avaliações do CSC na ALGAR e na ALCOA

\begin{tabular}{|c|c|c|}
\hline ASSUNTO & ALGAR & ALCOA \\
\hline $\begin{array}{l}\text { Objetivos (comuns) da } \\
\text { existência do CSC }\end{array}$ & $\begin{array}{l}\text { Redução de custos, otimização } \\
\text { de processos, ganho de escala, } \\
\text { viabilização do foco nas } \\
\text { atividades-fins pelas unidades de } \\
\text { negócio, padronização. } \\
\text { Foco predominante: redução de } \\
\text { custos. }\end{array}$ & $\begin{array}{l}\text { Redução de custos, otimização de } \\
\text { processos, ganho de escala, } \\
\text { viabilização do foco nas atividades-fins } \\
\text { pelas unidades de negócio, } \\
\text { padronização. } \\
\text { Focos predominantes: otimização e } \\
\text { minimização de custos, qualidade } \\
\text { prestação de serviços e agregação valor } \\
\text { às atividades clientes e organização. }\end{array}$ \\
\hline $\begin{array}{l}\text { Agregação de valor às } \\
\text { atividades internas e aos } \\
\text { negócios da organização }\end{array}$ & $\begin{array}{l}\text { Principalmente na execução de } \\
\text { atividades de back office, } \\
\text { possibilitando as empresas da } \\
\text { holding focar em seu negócio, e } \\
\text { ao grupo conseguir melhoria } \\
\text { significativa no seu faturamento. }\end{array}$ & $\begin{array}{l}\text { Pela qualidade dos serviços prestados, } \\
\text { pela pró-atividade em melhorar as } \\
\text { atividades, pelo desenvolvimento de } \\
\text { confiança e parceria junto às áreas } \\
\text { clientes, e pela capacidade de absorção } \\
\text { de outros serviços que porventura } \\
\text { venham a ser necessários à empresa. }\end{array}$ \\
\hline $\begin{array}{l}\text { Relacionamento do CSC com } \\
\text { as áreas clientes e vice-versa }\end{array}$ & $\begin{array}{l}\text { Considerado atualmente como } \\
\text { bom, mas com possibilidade de } \\
\text { melhoria do atendimento. }\end{array}$ & $\begin{array}{l}\text { Elevado grau de avaliação positiva tanto } \\
\text { no que se refere à questão do } \\
\text { relacionamento quanto do atendimento } \\
\text { em relação ao CSC. }\end{array}$ \\
\hline $\begin{array}{l}\text { Forma de avaliação dos } \\
\text { serviços prestados pelo CSC }\end{array}$ & $\begin{array}{l}\text { Contrato, SLA (Service Level } \\
\text { Agreement), reuniões. }\end{array}$ & $\begin{array}{l}\text { SLA (Service Level Agreement), SLM } \\
\text { (Service Level Management), avaliação } \\
\text { após cada prestação de serviço, busca } \\
\text { de esclarecimentos pelo CSC de } \\
\text { eventual atendimento inadequado, } \\
\text { controle sistemático de satisfação do } \\
\text { cliente. }\end{array}$ \\
\hline Nível de desempenho & $\begin{array}{l}\text { Bem avaliado atualmente, apesar } \\
\text { de uma série de melhorias que } \\
\text { ainda poderiam ser } \\
\text { implementadas, permitindo a } \\
\text { inferência que esta avaliação } \\
\text { resulta do fato de o modelo ter } \\
\text { sido considerado, } \\
\text { preponderantemente, somente } \\
\text { como uma empresa que deveria } \\
\text { ser especializada na execução } \\
\text { de atividades de back office. }\end{array}$ & $\begin{array}{l}\text { Bem avaliado em todos os sentidos, com } \\
\text { sinalização de ser um modelo com } \\
\text { considerável estágio de maturidade. }\end{array}$ \\
\hline $\begin{array}{l}\text { Atingimento dos benefícios } \\
\text { tangíveis e intangíveis }\end{array}$ & Predominante os tangíveis. & Mesclagem de tangíveis e intangíveis. \\
\hline $\begin{array}{c}\text { Avaliação geral, } \\
\text { considerando os respectivos } \\
\text { contextos e visão das } \\
\text { empresas na implementação } \\
\text { do modelo }\end{array}$ & $\begin{array}{l}\text { Modelo tem efetivamente o } \\
\text { condão de agregar valor aos } \\
\text { resultados das organizações, } \\
\text { viabilizando melhor desempenho } \\
\text { das empresas que o adotam. }\end{array}$ & $\begin{array}{l}\text { Modelo tem efetivamente o condão de } \\
\text { agregar valor aos resultados das } \\
\text { organizações, viabilizando melhor } \\
\text { desempenho das empresas que } 0 \\
\text { adotam. }\end{array}$ \\
\hline
\end{tabular}

Fonte: Dados da pesquisa. 


\subsection{Considerações sobre os modelos de serviços compartilhados da ALGAR e da ALCOA}

Considerando as manifestações dos entrevistados sobre o assunto, tem-se que, para ambas as empresas pesquisadas, os principais fatores motivadores para adoção do modelo de CSC, bem como 0 entendimento de que tal modelo acarretou vantagem competitiva por meio de facilitação do desenvolvimento de competências essenciais, estão em consonância com o abordado na teoria.

Mostrou-se diferenciada a concepção do CSC adotado por cada empresa, sendo que na ALCOA o modelo pode ser classificado como de "Marketplace", enquanto na ALGAR o modelo pode ser classificado como de "Empresa independente", considerando a total terceirização de execução dos serviços de back office.

Ressalte-se que cada empresa adotou um modelo diferenciado de CSC: - a ALGAR por um CSC totalmente terceirizado, muito possivelmente motivado pela insipiência do modelo nas organizações brasileiras à época (2001), bem como pela propagação de terceirização de serviços que predominava como uma das alternativas de gestão organizacional nesse mesmo período; - a ALCOA, por um CSC totalmente internalizado como uma unidade autônoma da própria empresa, decorrente, nesse caso, da experiência bem-sucedida de outros CSC da própria organização em outros locais no mundo, além da possibilidade de validação do modelo em comparação aos já existentes no Brasil à época da respectiva implementação (2005).

Destaque para o foco predominante da ALGAR com o CSC quanto à ênfase na redução de custos, uma das características mais preponderantes para decisão de um processo de terceirização.

\subsubsection{Processo de implementação do CSC}

A metodologia para implementação do CSC variou de acordo com a forma como foi concebido o modelo para sua adoção. Em relação à ALGAR, o CSC foi concebido de forma totalmente terceirizada, com o auxílio de consultoria escolhida para tal fim, e com dedicação exclusiva para atendimento à empresa, enquanto a ALCOA optou por um CSC totalmente internalizado na empresa com efetivo próprio. Os trabalhos preparatórios para o real funcionamento do modelo foram mais longos na primeira empresa citada do que na segunda, a qual inclusive já possuía conhecimento e experiência em relação ao assunto face outros CSCs da organização em outros lugares do mundo.

Pelo que se depreende das entrevistas, a ALGAR enfrentou problemas variados quando da implementação do CSC, ao contrário da ALCOA, cujos problemas foram mais localizados e aparentemente de mais fácil tratamento.

Em relação às dificuldades na ALGAR (Quadro 2), pode-se inferir a abordagem de problemas característicos de um processo de terceirização, no qual a empresa não tem domínio pleno das possibilidades de intervenção para promover maior adequação às suas necessidades, já as dificuldades na ALCOA (Quadro 3), pode-se inferir tratar-se de ajustes de aprimoramento passíveis de serem tratados pela própria organização.

Observa-se, pelo exposto nas entrevistas realizadas na ALGAR, que as medidas adotadas para tratamento desses problemas não conseguiram debelá-los na sua totalidade, alguns ainda causando efeitos negativos até hoje, motivo inclusive de a organização estar em fase de revisão do seu modelo de serviços compartilhados.

Na ALCOA, os problemas detectados relacionavam-se basicamente ao entendimento das Unidades de Negócios (também chamadas internamente de plantas) da empresa quanto às atividades que o CSC iria executar e seus impactos nas atividades realizadas por aqueles órgãos, bem como questões relacionadas à estrutura física. As medidas de tratamento desses problemas parecem ter surtido o efeito desejado, já que, do apurado nas entrevistas, denota-se que, além dos participantes informarem sobre a efetividade das ações, também não são relatados, pelo menos da forma como ocorreu quando da implementação, impactos significativos desses itens no desempenho do CSC na atualidade.

Além disso, na ALGAR, cujo CSC foi totalmente terceirizado e implementado em conjunto com uma consultoria externa, a ocorrência de constantes ajustes e necessidades de aprimoramento na fase de funcionamento do modelo fez com que essa fase de implementação e amadurecimento do CSC passasse por significativas oscilações desde seu início de funcionamento em 2001, a ponto de quase o contrato ter sido rescindido em 2007. As dificuldades foram principalmente decorrentes de revisão de domínio das informações e dos sistemas de melhoria na prestação dos serviços e na adequação do relacionamento com a forma de procedimento da empresa contratada. 
Ao contrário do que parece ter ocorrido na ALCOA, em que o CSC constituiu-se em um órgão interno da empresa com início de funcionamento em 2005 e, conforme manifestações dos entrevistados, as oportunidades de alteração e aprimoramento em relação ao processo de implementação do modelo estão muito mais relacionadas à busca da melhoria da qualidade na prestação de suas atividades do que a correção ou a adequação de algum fator decorrente da concepção e do processo de implementação do modelo em si.

\subsubsection{Implicações do CSC na estrutura organizacional}

Em ambas as empresas pesquisadas, a estrutura organizacional foi afetada de forma diferenciada: - na ALGAR, com um CSC operado por uma empresa terceirizada, ocorreu, dentre outros impactos, a redefinição dos níveis de responsabilidades de cada empresa, a reanálise da necessidade de espaço e equipamentos face a diminuição da quantidade de empregados, e a readequação da forma como cada empresa administra as atividades em função do relacionamento e da existência do CSC externo à empresa; - na ALCOA, constituiu-se de um novo órgão da organização, acrescido ao seu organograma, tanto em termos de competências, níveis hierárquicos e cargos, bem como alocação específica de mão de obra e demais recursos.

Mostrou-se diferenciado o modelo de governança corporativa do CSC em cada empresa, sendo que na ALCOA pode ser classificado como "modelo baseado em Unidade de Negócio independente", enquanto na ALGAR pode ser classificado como de "modelo baseado em holding" (corporativo), considerando a total terceirização de execução dos serviços de back office, com boa aderência aos prós e contras previsto para essa classificação, conforme Figura 1.

\subsubsection{Implicações do CSC na gestão de processos}

A centralização de atividades no CSC foi diferenciada entre as empresas na forma como foi realizada, no nível de maturação de execução em que se encontrava cada processo, bem como no modo como ocorreria o inter-relacionamento entre o CSC e a área cliente em relação aos respectivos processos.

Na ALGAR, a transferência ocorreu não somente dos processos, mas também dos recursos, principalmente humanos, que anteriormente executavam a atividade. A sensação de perda de inteligência por parte das empresas da ALGAR fez-se presente.

$\mathrm{Na}$ ALCOA, talvez pela forma mais padronizada como executava os processos, bem como as experiências com outros CSC da empresa no mundo, os relatos dão conta que eventuais padronizações de processos ocorreram posteriormente, mas sem percepção de mudança significativa pelos entrevistados.

Em ambas as empresas, as prestações de serviços às áreas clientes são realizadas procurando 0 máximo de padronização nos procedimentos, mas ainda existindo margem de diferenciação devido às eventuais peculiaridades dessas áreas, fato este mais destacado na ALGAR. O foco, entretanto, é a padronização, sempre que possível.

Em ambos os casos pesquisados, existem ferramentas que regulam o funcionamento do CSC em relação às áreas clientes em termos e direitos, deveres, qualidade de serviços, etc.:

- na ALGAR, basicamente são constituídas pelo contrato inicialmente firmado quando da contratação do CSC, adicionado de "aditivos" que se constituem no SLA (Service Level Agreement);

- na ALCOA, basicamente são constituídas pelo SLM (Service Level Management) e pelo SLA (Service Level Agreement), os quais contemplariam indicadores de valor, de qualidade e de gestão.

Analisando a forma como seria o acompanhamento e a medição da qualidade dos serviços prestados no CSC, foram apuradas situações diferenciadas, as quais, por inferência, pode-se atribuir que estejam vinculadas ao fato de ser um CSC terceirizado e um CSC interno à organização:

- na ALGAR, as áreas clientes se atêm à cobrança dos indicadores pactuados no contrato, SLA e resolução de problemas, não sendo detectado instrumento consistente de mensuração desses resultados;

- na ALCOA, a cobrança das áreas clientes é maior e a preocupação do CSC com essas também se estabeleceu de igual forma a mostrar a eficiência e a eficácia da prestação dos serviços acordados, motivo pelo qual existem várias formas de medição para aprimoramento dos serviços.

Revista Alcance - Eletrônica - vol. 22 - n. 2 - abr.jjun. 2015 
No que tange às dificuldades encontradas na adequação da execução dos processos/atividades pelo CSC em relação à área cliente e às ações tomadas para tratamento dessas dificuldades, a realidade encontrada nas duas empresas pesquisadas também foram de natureza distinta:

- na ALGAR, as dificuldades aconteceram em relação à própria forma como o processo/atividade passou a ser realizada pelo CSC terceirizado, passando pela pessoalidade entre os empregados do CSC e os da empresa da holding, e a falta de maior e melhor formalização, bem como a instituição de uma execução dos processos/atividades com maior efetividade;

- na ALCOA, as dificuldades aconteceram em relação à adaptação e ao gerenciamento dos empregados, não somente devido à sua adaptação no novo serviço e na localidade, mas também no trabalho em equipe dentro do objetivo proposto pelo CSC, bem como em relação à preocupação em executar processos com qualidade e demonstrar isso às áreas clientes.

\subsubsection{Implicação do CSC na gestão de pessoas}

As dificuldades/problemas em relação às pessoas quando da implementação e da consolidação dos CSCs ocorreram de forma bem diferenciada:

- na ALGAR, que possui CSC terceirizado, foi demonstrada a preocupação (e até mesmo a necessidade) para que os empregados que faziam as atividades que seriam executadas pelo CSC fossem contratados pelo mesmo;

- na ALCOA, cujo CSC é uma unidade da organização, a preocupação foi muito mais na demonstração para as áreas envolvidas dos benefícios que o modelo iria acarretar para a Unidade, na capacitação dos gestores como facilitadores da mudança, nas informações aos empregados e aos demais envolvidos sobre o desenvolvimento de cada etapa do processo.

Na pesquisa sobre os impactos do CSC em relação à mudança na cultura organizacional, além dos impactos que comumente ocorrem para adaptação da organização a esse modelo, merecem ser ressaltadas as seguintes situações, dentre outras:

- no caso da ALGAR, a insegurança gerada pela mudança de empregados para o CSC; a necessidade de que seus empregados/gestores se adaptar ao relacionamento com outra empresa externa prestadora de serviço, cujos controles e atuações são limitados pelo contrato de prestação de serviço e pela autonomia de decisão administrativa/operacional daquela empresa;

- no caso da ALCOA, a forma de atuação dos empregados, que passaram a ter autonomia individual para a prática de várias ações de seu interesse não mais dependendo de solicitação a outros órgãos; a demonstração da qualidade da prestação dos serviços de back office; a capacitação dos empregados do CSC com a visão de atuação não somente de prestação de serviço direcionado sempre ao melhor atendimento às necessidades das áreas clientes, mas também com a filosofia de instigar melhoramentos em toda a cadeia produtiva.

Pesquisando sobre a existência de medidas de produtividade de gestores e empregados no CSC, bem como de eventual existência de benefícios ou incentivos atrelados ao nível de serviço ou ao desempenho individual e de equipe, foi possível apurar que:

- no CSC da ALGAR predomina a avaliação por equipe, embora também exista uma avaliação individual, mas esta com um forte viés de subjetividade, sendo que estão estudando uma metodologia mais adequada para medição individual de produtividade;

- no CSC da ALCOA, o sistema de avaliação é bem estruturado, com avaliações de indicadores individuais, contratos de expectativas e avaliação 360 . Em termos de progressão de carreira, têm-se as graduações no próprio cargo e a possibilidade de ascensão às funções gerenciais e consultivas.

No que tange à forma de seleção de empregados para trabalhar no CSC, a realidade nas duas empresas pesquisadas se mostra diferenciada:

- no CSC terceirizado da ALGAR foi possível apurar que a forma preponderante de seleção e contratação de pessoas é por indicações, avaliada por critérios de melhor aderência nesse formato de trabalho;

- no caso do CSC da ALCOA foi manifestada a existência de critérios básicos para contratação; na seleção, são verificados atributos técnicos para a respectiva posição de trabalho, também chamada de perfil. As vagas são 
primeiramente oferecidas internamente, visando ao preenchimento pelos próprios empregados da ALCOA que possuam o perfil exigido.

Uma sinalização possível de ser feita, à luz do anteriormente exposto, é que a viabilização de tal conjunto de ações em relação às pessoas parece ser mais facilitada e efetiva em relação aos CSCs que se constituem Unidade autônoma da própria organização a que pertencem.

\subsubsection{Gestão das mudanças para implementação do CSC}

O ponto mais significativo nessa questão da mudança em relação ao CSC terceirizado da ALGAR decorreu da forma de administração e solução dos problemas à medida que ocorriam, os quais foram sendo resolvidos, até mesmo por falta de melhor alternativa, com a parceria da empresa ALGAR com o CSC, fator principal para a viabilização de continuidade de prestação dos serviços do CSC às empresas da ALGAR até hoje.

Apesar de ao longo do tempo a relação entre o CSC terceirizado e as empresas da ALGAR apresentar oscilações de turbulência e tranquilidade, o fato é que foram obtidos ganhos por ambas as partes, além de uma oportunidade de crescimento única com tal experiência de adoção do modelo. Devido ao fim do período do contrato inicialmente firmado, já se vislumbram necessidades de adequações e reanálises tanto da questão de governança corporativa em relação ao CSC, quanto da incorporação da conscientização da necessidade de preparar melhor o cliente para o modelo de CSC, com um melhor gerenciamento da mudança.

O ponto mais significativo nessa questão de mudança em relação ao CSC da ALCOA foi o processo de preparação dos envolvidos, principalmente as áreas clientes, sobre 0 entendimento do que significava o CSC para suas operações e a demonstração da efetividade da prestação de serviço em curto espaço de tempo da implementação do CSC, o que propiciou que o modelo pudesse apresentar resultados de forma mais rápida e aparentemente propiciar atendimento com qualidade e confiança para as empresas servidas, e efetiva percepção de liberação das áreas fins para focar no seu negócio.

Considerando o referencial teórico sobre 0 assunto, assim como 0 apurado nas entrevistas, pode-se inferir que o processo de gestão da mudança para a implementação do CSC foi mais bem sucedido no CSC da ALCOA, considerando que no CSC da ALGAR, além do maior número de dificuldades já relatadas, até hoje persistem problemas de relacionamento e qualidade de prestação do serviço, motivo também pelo qual o modelo do CSC nesta empresa está sendo revisto.

\section{CONSIDERAÇÕES FINAIS}

O modelo de CSC permite a empresa focar em suas competências centrais, com aumento da vantagem competitiva na sua cadeia de valor. Contudo, os objetivos que fundamentam a sua adoção, em especial quanto à constituição de uma unidade própria ou terceirizada, diferenciam o tipo de vantagem competitiva alcançada.

Dessa forma, por exemplo, enquanto uma empresa adotou o CSC como uma forma predominante de redução de custos e de desoneração das áreas fins para concentração no seu foco de atuação, a outra empresa, além desses fatores, também buscou a atuação do CSC como gerador de benefícios intangíveis, bem como parceiro das áreas clientes.

As dificuldades de implementação do modelo tendem a residir principalmente nos aspectos vinculados ao planejamento dessa etapa e no grau de conhecimento de situações semelhantes no mercado. Nesse particular, em relação ao processo de implementação de um CSC, pode-se ressaltar as peculiaridades inerentes a ser um órgão interno da organização que o adota, ou ser totalmente terceirizado, acarretando, inclusive para este último caso, todo um contexto peculiar inerente à contratação e à gestão de serviços terceirizados.

Ressalte-se a influência dos objetivos e das expectativas que nortearam a decisão de adoção de modelo na execução dos processos pelo CSC. No caso de o modelo ter sido concebido somente para executar as atividades de back office anteriormente realizadas pelas áreas fins, a tendência é que a organização se restrinja a cobrar 0 acordado em contrato e não possa esperar outro tipo de atuação do CSC na agregação de valor aos serviços da empresa. 
Para situação como a relatada no parágrafo anterior, a sigla CSC seria mais bem identificada como Centro de Serviço "Centralizado", e não compartilhado, ao contrário de um modelo de CSC cuja atuação é também pautada pelo relacionamento de parceria com as áreas clientes para o comum atingimento dos objetivos estratégicos da organização. Para esse tipo de centralização de atividades, uma inferência possível de ser realizada é a de que existe a tendência de as áreas clientes serem obrigadas a se subordinar à forma de execução das atividades de suporte do CSC, mesmo que essa execução seja deficitária, ocasião em que afetará negativamente as atividades-fins da área cliente.

Os critérios de contratação, treinamento e capacitação, análise de desempenho e benefícios para os empregados do CSC são fatores fundamentais para o nível de qualidade que se espera da prestação do serviço às áreas clientes, corroborando com a abordagem teórica sobre 0 assunto. Nesse particular, uma inferência possivel de ser realizada a partir dos estudos de casos realizados é a de que um CSC atuante como partícipe e parceiro das áreas clientes na melhoria contínua dos processos e atingimento dos resultados estratégicos da organização, com foco além da somente execução rotineira das atividades, tende a investir mais na seleção, capacitação e qualificação dos seus empregados.

Respeitados os objetivos que fundamentaram a decisão de adoção do CSC nas empresas pesquisadas, a formatação definida - terceirização interna ou externa, as diferentes expectativas geradas e as diferentes dificuldades vivenciadas, ambas o avaliaram bem, considerando-o capaz de agregar valor à organização, diferenciando-a ou ajudando-a a se destacar no mercado, o que ratifica a teoria sobre o assunto no que tange à viabilidade técnica, econômica e gerencial do modelo para as organizações.

Os benefícios, os resultados e a gestão do CSC apontados pela teoria foram corroborados pela pesquisa, a qual também demonstrou que a otimização dos mesmos depende intrinsecamente da forma como as empresas tratam o modelo desde a sua adoção até a sua manutenção. No presente estudo, tal otimização foi notada mais facilitada em CSC operado pela própria organização, em detrimento ao CSC terceirizado, o qual apresenta dificuldades operacionais inerentes à forma como os serviços são executados e geridos por empresa contratada, geralmente vinculado por instrumento contratual.

Oportuno relembrar Schulman, Harmer e Lusk (2001), no que tange à alusão de que o poder da execução dos serviços compartilhados por unidade própria da organização e da terceirização não está em simplesmente diminuir os custos de transação de uma só vez, mas de um contínuo desenvolvimento do processo num modo de parceria eficiente para fornecer sempre os melhores serviços a custos baixos, o que enfatiza ainda mais a visão de longo prazo para usufruir de aprimoramentos constantes na vantagem competitiva gerada.

Por fim, contribuí-se com a sugestão para realização de pesquisas sobre os seguintes temas, avaliados como de maior destaque: a) CSC em empresas familiares, considerando em especial os aspectos culturais e de gestão característicos desse tipo de organização; b) CSC em órgãos da Administração Pública Direta e Indireta, como instrumento de agregação de valor ao atendimento da sociedade e de otimização de processos internos, considerando as características peculiares da gestão pública; c) CSC como modelo estratégico de aliança interorganizacionais; d) CSC como modelo de estratégia para competitividade de empresas que atuam internacionalmente.

\section{REFERÊNCIAS}

BAIN \& COMPANY. Centro de serviços compartilhados: uma solução definitiva para processos administrativos? 2004. Disponível em: http://www.bain.com/. Acesso em: 22 nov. 2009.

BARDIN, L. Análise de conteúdo. 3. ed. Lisboa: Edições 70, 2004.

BERGERON, B. Essentials of shared services. New Jersey: John Wiley \& Sons, 2003.

LOZINSKY, S. Serviços compartilhados como melhor prática. São Paulo: IBM Global Business Services, 2006. Disponivel em: <http://www.ibm.com/br/l>. Acesso em: 22 nov. 2009.

MAGALHÃES, C. Passo a passo para planejamento, estruturação, estratégias e processos de um Centro de Serviços Compartilhados. São Paulo: Conexões Educação Empresarial, 2009, 160 p. 
MARTINS. V.P.; AMARAL, F.P. A consolidação da prática de serviços compartilhados. 2008. Dissertação (Mestrado em Gestão de Negócios) - Universidade Católica de Santos, Santos, 2008. Disponível em: <http://www.unisantos.br/>. Acesso em: 22 nov. 2009.

PEREIRA, N. A. F. Impactos da implantação do centro de serviços compartilhados sobre sistemas de controles: estudos de caso. 2004. Dissertação (Mestrado em Administração) - Pontifícia Universidade Católica do Paraná, Curitiba, 2004.2 Disponível em: <http://www.biblioteca.pucpr.br/tede//tde_busca/arquivo.php?codArquivo=191>. Acesso em: 22 nov. 2009.

PORTER, M. (Org.). Estratégia: a busca da vantagem competitiva. Rio de Janeiro: Elsevier, 1998.

QUINN, B.; COOKE, R.; KRIS, A. Shared services: mining for corporate gold. London: Financial TimesPrentice Hall, 2000 apud RAMOS, L. J. T. Serviços compartilhados como forma de estruturação organizacional. 2005. Dissertação (Mestrado em Administração) - Universidade Federal da Bahia, Salvador, 2005. Disponível em: <http://www.dominiopublico.gov.br/download/texto/ea000305.pdf>. Acesso em: 10 jan.2010.

RAMOS, L. J. T. Serviços compartilhados como forma de estruturação organizacional. 2005. Dissertação (Mestrado em Administração) - Universidade Federal da Bahia, Salvador, 2005. Disponível em: <http://www.dominiopublico.gov.br/download/texto/ea000305.pdf>. Acesso em: 10 jan. 2010.

SILVA, E. D.; PEREIRA, N. A. F. Centro de serviços compartilhados e a gestão de vínculos: uma análise integrada. Revista Alcance, Itajaí, v. 11, n. 1, p. 49-64, jan./abr. 2004. Disponível em: <http://siaiweb06.univali.br/seer/index.php/ra/article/viewFile/1794/1421>. Acesso em: 22 nov. 2009.

SILVA, J.A.T; SANTOS, R.F; SANTOS, N.M.B. Criando valor com serviços compartilhados: aplicação do balanced scorecard. São Paulo: Saraiva, 2006

SHAH, B. Shared services: is it for you? Industrial Management, Norcross, v. 40, n.5, 1998.

SCHULMAN, D.; HARMER, M.; LUSK, J. Shared Services: agregando valor às unidades de negócios. São Paulo: MAKRON Books, 2001. 